\title{
Does Neighborhood Deterioration Lead to Poor Health?
}

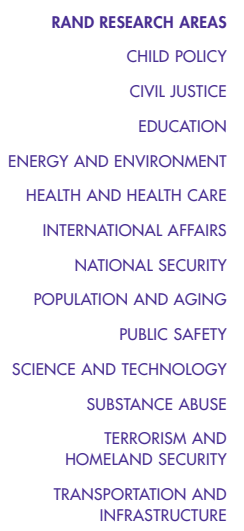

This product is part of the RAND Corporation research brief series. RAND research briefs present policy-oriented summaries of individual published, peer-reviewed documents or of a body of published work.

Corporate Headquarters 1776 Main Stree P.O. Box 2138 Santa Monica, California 90407-2138 Tel 310.393 .0411 Fax 310.393 .4818

(C) RAND 2005
$\mathrm{P}$

oorer people tend to have poorer

health. For example, researchers have observed that rates of obesity, injury, and asthma among children and adolescents differ along socioeconomic lines. Poorer people also tend to have higher rates of premature death (before 65 years of age). While some health problems might be explained by lifestyle (e.g., high-fat diets, smoking), it is not known why poorer people have unhealthier lifestyles. More broadly, it is unclear why relative poverty-defined in relation to the average resources available in a society and not necessarily to a lack of sufficient food, clothing, or shelter-is related to poor health.

Given that people of similar socioeconomic status tend to live near each other, it may be that the physical condition of some impoverished neighborhoods can affect residents' health. For example, researchers have found connections between the deterioration of the inner city and the spread of HIV, tuberculosis, and other health conditions. Studies have also found that the appearance and design of buildings and streets can facilitate crime.

A team of experts led by RAND's Deborah Cohen have been examining these issues. Their research has focused on whether residents

\section{Key findings:}

- Even after controlling for poverty, residents of deteriorated neighborhoods had higher rates of gonorrhea, premature death in general, and death from cardiovascular disease and homicide.

- A neighborhood's collective efficacyi.e., residents' willingness to help out for the common good-was associated, after controlling for poverty, with lower rates of premature death in general and death from cardiovascular disease and homicide.

- However, the association between collective efficacy and lower rates of premature death was not seen in neighborhoods with a high percentage of boarded-up stores and homes, litter, and graffiti.

of neighborhoods with a high percentage of boarded-up stores and homes, litter, and graffiti (what political scientist James Q. Wilson has referred to collectively as "broken windows") experience a higher incidence of disease and premature death than do people who live in neighborhoods that are not deteriorated.

\section{This Highlight summarizes RAND Health research reported in the following publications:}

Cohen D., K. Mason, A. Bedimo, R. Scribner, V. Basolo, and T. Farley, "Neighborhood Physical Conditions and Health," American Journal of Public Health, Vol. 93, No. 3, 2003, pp. 467-471.

Cohen D., S. Spear, R. Scribner, P. Kissinger, K. Mason, and J. Wildgen, “'Broken Windows' and the Risk of Gonorrhea," American Journal of Public Health, Vol. 90, No. 2, 2000, pp. 230-236.

Cohen D., T. Farley, and K. Mason, "Why Is Poverty Unhealthy? Social and Physical Mediators," Social Science and Medicine, Vol. 57, No. 9, 2003, pp. 1631-1641. 
Their key findings:

- Even after controlling for poverty, residents of deteriorated neighborhoods had higher rates of gonorrhea, premature death in general, and death from cardiovascular disease and homicide.

- A neighborhood's collective efficacy-i.e., residents' willingness to help out for the common good-was associated, after controlling for poverty, with lower rates of premature death in general and death from cardiovascular disease and homicide.

- However, the association between collective efficacy and lower rates of premature death was not seen in neighborhoods with a high percentage of boarded-up stores and homes, litter, and graffiti.

\section{"Broken Windows" and Health}

James Q. Wilson's "Broken Windows" theory suggests that disorder in the physical environment can be associated with crime: "If a broken window is unrepaired, all the windows will soon be broken. Broken windows are a signal that no one cares." The theory suggests that a neighborhood's physical condition sends out messages about the kinds of behavior that are permitted. A neglected and disorderly physical environment signals to residents that behaviors that are usually prohibited are tolerated.

Figure 1 provides an example of how the broken windows concept might be used to understand health issues. The figure illustrates how neighborhood conditions might affect residents' health by inhibiting or facilitating risk-taking behavior, by influencing social relationships, and by exposing residents to visual cues that can arouse fear, anxiety, and depression.

\section{Figure 1}

How the Physical Environment Might Influence Health

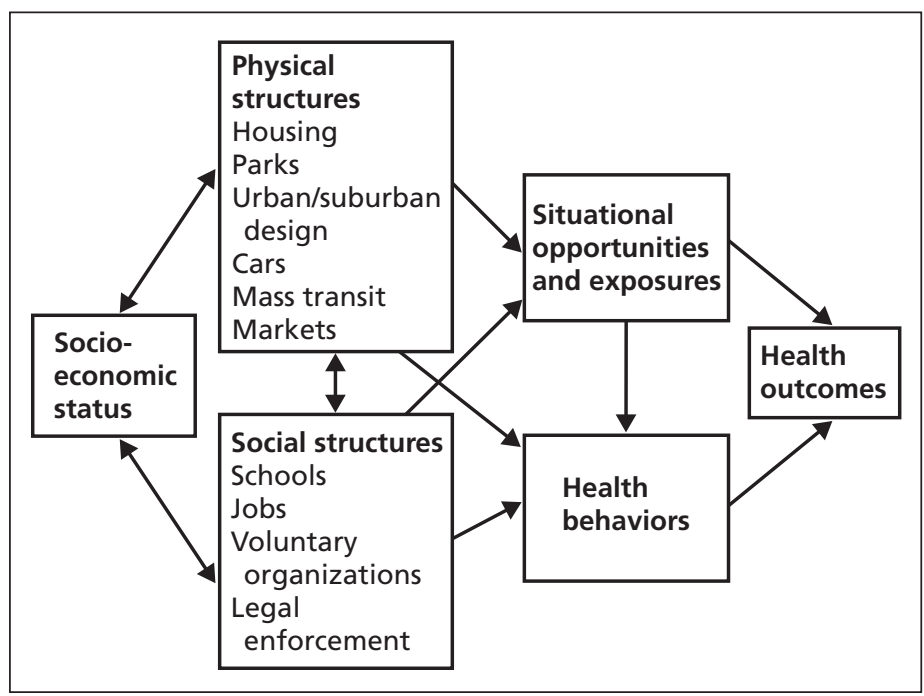

Residents of Deteriorated Neighborhoods Have Higher Rates of Gonorrhea, Premature Death, and Other Health Conditions

The research team (which included researchers from the New Orleans area) created a "broken windows index" to examine the possible association of neighborhood deterioration and high-risk sexual behavior and gonorrhea rates in 55 New Orleans neighborhoods. The index is a scale representing conditions in the neighborhood, and it accounts for such problems as trash, abandoned cars, graffiti, and homes and schools in poor repair. Researchers mapped all cases of gonorrhea between 1994 and 1996 and calculated the rate of disease by neighborhood "block group" (each block group consisted of several city blocks as designated by the U.S. Census). Using data from the 1990 U.S. Census and 1995 updates, they determined the relationship between gonorrhea rates, neighborhood deterioration, and poverty and other demographic characteristics.

The broken windows index was found to be a significant predictor of gonorrhea rates. Poor neighborhoods with high broken windows scores had significantly higher gonorrhea rates than did poor neighborhoods with low broken windows scores. Indeed, the level of neighborhood deterioration as measured by the broken windows index was a better predictor of neighborhood gonorrhea rates than were demographic characteristics as measured by a poverty index.

Figure 2 shows an example of a high-poverty neighborhood with a high gonorrhea rate.

Expanding on the New Orleans study, the research team analyzed U.S. Census data on 107 cities with populations over 150,000. This study used the U.S. Census measure of

\section{Figure 2}

High-Gonorrhea, High-Poverty Neighborhood, New Orleans, Louisiana

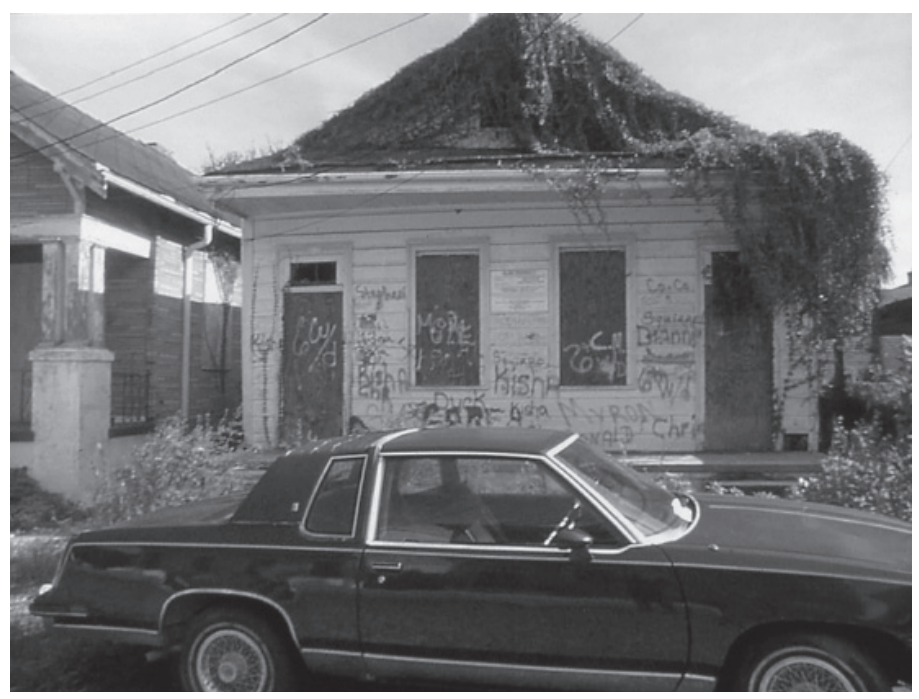


"boarded-up units per square mile" as a proxy for neighborhood deterioration. A vacant house was considered "boarded up" if there were physical signs that the house was not habitable, such as boards secured over doors and windows. In most cases, such housing units were visibly deteriorated. This measure was very similar to the broken windows index used in the aforementioned study.

The researchers found that, after controlling for sociodemographic factors, neighborhoods with a high number of boarded-up vacant housing units also had higher rates of premature death from all causes and from several specific causes (e.g., diabetes, homicide, suicide) and higher rates of sexually transmitted diseases.

\section{Residents' Willingness to Help Each Other Out Is Generally Associated with Better Health, Although Not in Highly Deteriorated Areas}

Neighborhood deterioration was not the only environmental factor found to be associated with residents' health status. The same research team conducted a related analysis of data from the Project on Human Development in Chicago Neighborhoods, finding that the residents' willingness to help out for the common good (known as a neighborhood's collective efficacy) appeared to be associated with lower rates of premature death in general and, specifically, deaths from cardiovascular disease and homicide. The study also found that in neighborhoods with few broken windows or other signs of deterioration, collective efficacy was associated with lower rates of premature death. However, this effect was not seen in neighborhoods with high rates of boarded-up, vacant housing units, graffiti, and trash on the streets.

\section{How Might Environment Affect Residents' Health?}

Although the findings of these studies indicate that individuals living in deteriorated neighborhoods have a higher risk of gonorrhea, premature death, and other health conditions, the researchers did not have sufficient information to determine whether neighborhood deterioration caused the health risks in those neighborhoods, nor whether collective efficacy caused residents of some well-kept neighborhoods to be healthier.

If the environment were found to cause certain health outcomes, it might do so in several ways.

One possibility is that an unsafe environment subject to vandalism and filled with graffiti, deterioration, trash, and abandoned cars provides a signal that there are no rules and that no one cares. Given an environment that tolerates behaviors that would otherwise be considered antisocial, residents may have few reasons not to engage in high-risk sexual, drug-use, and other unhealthy behaviors.
In addition, areas with boarded-up housing are usually considered dangerous and thus can generate fear among residents and outsiders alike. Fewer commercial businesses, including markets and health clubs, might be conveniently accessible, either because of lower demand or because fearful business owners prefer to locate elsewhere. It is also possible that residents of such areas might feel fearful of walking or exercising outdoors in their neighborhoods. Consequently, neighborhood conditions might discourage residents from exercising, eating nutritious foods, or adopting other healthful behaviors that could otherwise protect them against heart disease, cancer, and diabetes.

On the other hand, the environment found in neighborhoods with high levels of collective efficacy might encourage residents to behave in more healthy ways. For example, residents of neighborhoods with greater collective efficacy are more likely to actively look out for and protect each other and thus to constrain the behaviors of potential wrong-doers; this supportive and protective environment might result in lower rates of death due to homicide. Moreover, residents of such neighborhoods are also likely to have greater levels of social support available-i.e., more and higher-quality relationships with other residents.

Studies have shown that individuals with higher levels of social support tend to live longer than those without such relationships.

But while it is possible that neighborhood conditions can affect residents' health, it is also plausible that residents' characteristics, behaviors, or some other unknown risk factors - and not the neighborhood-are the cause of health outcomes. In other words, deteriorated neighborhoods may simply be markers for high-risk personalities or persons who do not take care of themselves (leading to poor health) or their surroundings (leading to neighborhood deterioration). Deteriorated neighborhoods may be home to a concentration of individuals who have few constraints on their behavior, engage in high-risk sexual or other unhealthy behavior (e.g., unprotected sex, smoking, alcohol use), and intentionally create a disorderly environment.

It is also possible that a dynamic relationship exists between people and their environment through which neighborhood conditions and residents' behavior influence each other. Over time, the deterioration of a neighborhood might cause families with means and traditional standards of behavior to leave the neighborhood or the city, and their departure then leads to the gradual disappearance of individuals who might serve as role models and work together for the common good. In the absence of counterbalancing forces, the norms of the street begin to prevail. 
In addition, the lack of an association seen between collective efficacy and lower rates of premature death in highly deteriorated neighborhoods suggests that the physical stigma of poverty and the implied tolerance of deviant behaviors in areas marked by graffiti and boarded-up homes may in some cases overwhelm the ability of people to act cooperatively for the greater good.

\section{Creating Healthier Neighborhoods}

These studies make clear that, while the traditional thinking about health in American society has been that the individual alone decides whether or not to engage in healthy or unhealthy behaviors, the conditions in which the individual lives may also contribute to his or her health and longevity. Although the research could not establish the cause-andeffect relationships between neighborhood conditions and health outcomes, future studies may be able to shed more light on the role of the environment in determining people's health. Understanding cause-and-effect relationships will require residents' health to be tracked at multiple points in time so that researchers can determine when and under what conditions individuals experience particular health outcomes. In addition, it will be necessary to control for individual behaviors (smoking, alcohol use) and other risk factors that might affect an individual's health.
Whether neighborhood deterioration literally encourages residents to behave in ways that are detrimental to their health, can potentially be addressed through enforcement of existing zoning and housing codes, civic efforts to keep streets clear and clean, and initiatives to find new uses for abandoned properties, including their potential transformation into green spaces and small parks. Cities might also support the development of local civic organizations and clubs, which can provide opportunities for a neighborhood to increase its collective efficacy by enhancing more positive social interactions and building social support networks among neighbors.

However, it is important to recognize that, beyond a certain point of neighborhood deterioration, it may not be possible to initiate viable or sustainable voluntary organizations where there are neither appropriate physical infrastructures to house them nor complementary structures that could provide additional support.

To advance the understanding of the link between manmade environments and health outcomes, RAND Health has recently established the Center for Population Health and Health Disparities. Among the chief aims of the Center are to study the effects of neighborhoods on health throughout the life cycle and to develop a risk data resource that can be used to enhance understanding of how neighborhoods influence health.

\footnotetext{
Abstracts of all RAND Health publications and full text of many research documents can be found on the RAND Health web site at www.rand.org/health. The RAND Corporation is a nonprofit research organization providing objective analysis and effective solutions that address the challenges facing the public and private sectors around the world. RAND's publications do not necessarily reflect the opinions of its research clients and sponsors. RAND ${ }^{\circledR}$ is a registered trademark.
}

RAND Offices Santa Monica - Washington - Pittsburgh • New York - Doha • Berlin - Cambridge • Leiden 


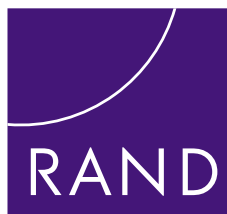

\section{HEALTH}

CHILD POLICY

CIVIL JUSTICE

EDUCATION

ENERGY AND ENVIRONMENT

HEALTH AND HEALTH CARE

INTERNATIONAL AFFAIRS

NATIONAL SECURITY

POPULATION AND AGING

PUBLIC SAFETY

SCIENCE AND TECHNOLOGY

SUBSTANCE ABUSE

TERRORISM AND HOMELAND SECURITY

TRANSPORTATION AND INFRASTRUCTURE
This PDF document was made available from www.rand.org as a public service of the RAND Corporation.

This product is part of the RAND Corporation research brief series. RAND research briefs present policy-oriented summaries of individual published, peerreviewed documents or of a body of published work.

The RAND Corporation is a nonprofit research organization providing objective analysis and effective solutions that address the challenges facing the public and private sectors around the world.

\section{Support RAND}

Browse Books \& Publications

$\underline{\text { Make a charitable contribution }}$

For More Information

\author{
Visit RAND at www.rand.org \\ Explore RAND Health \\ View document details
}

Limited Electronic Distribution Rights

This document and trademark(s) contained herein are protected by law as indicated in a notice appearing later in this work. This electronic representation of RAND intellectual property is provided for noncommercial use only. Permission is required from RAND to reproduce, or reuse in another form, any of our research documents for commercial use. 